\title{
Effects of secretome on cisplatin-induced testicular dysfunction in rats
}

\author{
Surya Agus Prihatno ${ }^{1}$, Irma Padeta ${ }^{2}$, Arinda Devi Larasati ${ }^{2}$, Betty Sundari ${ }^{2}$, Annisa Hidayati ${ }^{2}$, Yuda Heru Fibrianto ${ }^{3}$ and \\ Teguh Budipitojo ${ }^{2}$
}

\begin{abstract}
1. Department of Reproduction and Obstetrics, Faculty of Veterinary Medicine, Universitas Gadjah Mada, Yogyakarta, 55821, Indonesia; 2. Department of Anatomy, Faculty of Veterinary Medicine, Universitas Gadjah Mada, Yogyakarta, 55821, Indonesia; 3. Department of Physiology, Faculty of Veterinary Medicine, Universitas Gadjah Mada, Yogyakarta, 55821, Indonesia.

Corresponding author: Teguh Budipitojo, e-mail: budipitojo@ugm.ac.id

Co-authors: SAP: prihatno@ugm.ac.id, IP: irmapadeta@ugm.ac.id, ADL: arinda.aja@gmail.com, BS: dkbetty96@gmail.com, AH: annisahidayati95@gmail.com, YHF: yuda@ugm.ac.id

Received: 18-05-2018, Accepted: 16-08-2018, Published online: 29-09-2018
\end{abstract}

doi: 10.14202/vetworld.2018.1349-1356 How to cite this article: Prihatno SA, Padeta I, Larasati AD, Sundari B, Hidayati A, Fibrianto YH, Budipitojo T (2018) Effects of secretome on cisplatin-induced testicular dysfunction in rats, Veterinary World, 11(9): 1349-1356.

\begin{abstract}
Background: Testicular dysfunction is a degenerative disorder characterized by failure in the synthesis of reproductive hormones and spermatogenesis. Secretome derived from the human umbilical mesenchymal stem cell (MSC) has been reported to repair some degenerative disorders.
\end{abstract}

Aim: This study aimed to investigate the effect of secretome derived from the human umbilical MSCs on cisplatin-induced testicular dysfunction in rats.

Materials and Methods: Thirty-six male Wistar rats were divided into the control and secretome-treated groups. In the secretome-treated group, testicular dysfunction was induced by $3 \mathrm{mg} / \mathrm{kg}$ BW of cisplatin intraperitoneally 3 times with 3 -day intervals. The secretome-treated group was divided according to dose: Low-dose $(0.2 \mathrm{~mL} / \mathrm{kg} \mathrm{BW})$ and high-dose $(0.5 \mathrm{~mL} / \mathrm{kg} \mathrm{BW})$ groups. Secretomes were injected intraperitoneally once a week for 3 weeks. 1 week after the injection of secretome, the cauda epididymis of the rats was removed for spermatozoa evaluation and histological examination.

Result: After the injection of secretome, the sperm motility of the high-dose group showed thin wave-like, rare, and slow movements. No abnormal sperm morphology was observed in all the treated groups. The number of spermatozoa increased gradually in the high-dose group after the injection of secretome. The developmental stages of the spermatogenic cells were complete in both spermatozoa groups after the injection of secretome. However, the spermatozoa in the seminiferous tubules of the high-dose group were denser. Vimentin and cytokeratin immunoreactivities were very strong in the high-dose group 1 week after the second secretome injection.

Conclusion: High-dose secretome derived from the human fetal umbilical cord could increase the number and motility of sperms in rats with cisplatin-induced testicular dysfunction. The administration of high-dose secretome was effective 1 week after the second dose, as indicated by very strong immunoreactivity for vimentin and cytokeratin. Moreover, secretome could promote the regeneration of the seminiferous tubules of both the groups.

Keywords: cisplatin, cytokeratin, secretome, spermatogenesis, testicular dysfunction, vimentin.

\section{Introduction}

Secretome is a factor found in the stem cell culture medium. This factor may repair the tissues of the organs that were damaged by various degenerative disorders [1]. A previous study has reported that secretome derived from the fetal human umbilical cord mesenchymal stem cell (HUC-MSC) may be an effective regenerative agent for $\beta$-cell pancreatic regeneration in Type 1 diabetes mellitus [2] and for skin regeneration in incisional [3] and burn wound healing [4]. The administration of cisplatin as a chemotherapeutic agent [5] is limited because it causes side effects,

Copyright: Prihatno, et al. Open Access. This article is distributed under the terms of the Creative Commons Attribution 4.0 International License (http://creativecommons.org/licenses/ by/4.0/), which permits unrestricted use, distribution, and reproduction in any medium, provided you give appropriate credit to the original author(s) and the source, provide a link to the Creative Commons license, and indicate if changes were made. The Creative Commons Public Domain Dedication waiver (http:// creativecommons.org/publicdomain/zero/1.0/) applies to the data made available in this article, unless otherwise stated. such as reproductive toxicity [6,7]. Moreover, it could decrease the number and motility of spermatozoa and increase abnormal spermatozoa morphology in patients with neoplastic disorders $[8,9]$.

Reproductive toxicity is caused by the suppression of steroidogenesis and the generation of free radicals, and then, it progresses to testicular dysfunction [10]. As a degenerative disorder, testicular dysfunction is characterized by failure in the synthesis of reproductive hormones and spermatogenesis. Vimentin and cytokeratin are intermediate filaments that support the structural formation and functioning of the spermatogenic cells, Sertoli, and Leydig cells. Cisplatin-induced testicular cell damage would promote vimentin and cytokeratin localization in the spermatogenic, Sertoli, and Leydig cells.

Studies on the use of secretome in promoting the recovery of various degenerative disorders and its effects on the spermatogenesis of rats with cisplatin-induced testicular dysfunction have not been 
conducted. Therefore, we aimed to investigate the effect of secretome derived from HUC-MSC on cisplatin-induced testicular dysfunction in rats.

\section{Materials and Methods \\ Ethical approval}

This study was approved by the Ethical Committee of the Universitas Gadjah Mada with the reference number 00035/04/LPPT/V/2017.

\section{Experimental animal}

Thirty-six male Wistar rats were adapted for 7 days before the administration of cisplatin, and these rats were fed with basal food and water ad libitum. Moreover, they were maintained at $12-\mathrm{h}$ light-dark cycle and were divided into the control and secretome-treated groups. Testicular dysfunction was induced by cisplatin at the dose of $3 \mathrm{mg} / \mathrm{kg}$ BW [11] intraperitoneally 3 times with 3 days' interval. Cisplatin was not administered in the control group. Then, the secretome-treated group was further divided into the low- and high-dose secretome-treated group. Secretomes were injected intraperitoneally once a week for 4 weeks at a dose of 0.2 and $0.5 \mathrm{~mL} / \mathrm{kg} \mathrm{BW}$ in the low- and high-dose secretome-treated groups, respectively. The rats were sacrificed every 1 week after the injection of secretome, and the cauda epididymis of the rat was collected for spermatozoa examination. Then, the testicles were collected for histological examination.

\section{Spermatozoa examination}

Sperm motility and morphology were evaluated after the cauda epididymis was immediately collected. The cauda epididymis was sliced in the Petri dish and diluted in saline solution at $37^{\circ} \mathrm{C}$. Sperm motility was assessed using the light microscope at $500 \times$ and was then graded according to a mass movement, as shown in Table-1. After the assessment of sperm motility, sperm morphology was immediately evaluated using the light microscope at $500 \times$. The number of sperm was measured using the Neubauer chamber and was counted as millions $/ \mathrm{mL}$. The results were descriptively and quantitatively analyzed.

\section{Hematoxylin and eosin (H\&E) staining}

Testicular morphology was examined using the H\&E method. The tissue slides were deparaffinized in xylene and rehydrated in gradual concentrations of ethanol for $5 \mathrm{~min}$. Then, they were incubated in Harris hematoxylin solution for $10 \mathrm{~min}$ at room temperature and rinsed in running water for $10 \mathrm{~min}$ before incubation in eosin solution for $20 \mathrm{~min}$ at room temperature. Finally, they were dehydrated in gradual concentrations

Table-1: Mass movement grade of spermatozoa.

\begin{tabular}{ll}
\hline Grade & Interpretation \\
\hline+++ & Dense, cloudy, and fast moving \\
++ & Thin waves and rare and slow movements \\
+ & Individual progressive movement \\
\hline
\end{tabular}

of ethanol for $3 \mathrm{~min}$, cleared in xylene for $5 \mathrm{~min}$, and mounted. The nucleus was visualized in purple color, and the cytoplasms were visualized in red color. The stained tissue slides were assessed using the light microscope with Optilab ${ }^{\circledR}$ camera. The morphology and structure of the spermatogenic cells in the seminiferous tubules were observed and analyzed descriptively.

\section{Vimentin and cytokeratin immunohistochemical staining}

Vimentin and cytokeratin immunolocalizations in the testicular tissues were visualized using the streptavidin-biotin complex method (Starr Trek Universal HRP Detection System Kit, Biocare Medical, USA). The tissue slides were deparaffinized and dehydrated and were then rinsed in running water for $10 \mathrm{~min}$. The tissue slides were incubated in blocking endogenous peroxidase solution for $20 \mathrm{~min}$ at room temperature and then rinsed with phosphate buffer saline (PBS) 3 times for $5 \mathrm{~min}$. The tissues were incubated in Biocare's background sniper solution for $20 \mathrm{~min}$ at room temperature. Anti-vimentin and anti-cytokeratin primary antibodies $(1: 100)$ were used on the tissue slides at $4^{\circ} \mathrm{C}$ overnight.

The tissue slides were rinsed in PBS 3 times for 5 min and were incubated in Trekkie Universal Link solution for $20 \mathrm{~min}$ at room temperature. Before incubation, the tissue slides were rinsed with PBS 3 times for $5 \mathrm{~min}$. Immunoreactive sites were visualized after using Betazoid DAB Chromogen solution (1:50) on the tissue slide at room temperature. Then, the tissue slides were counterstained with Harris hematoxylin and rinsed in running water for 10 min before being dehydrated, cleared, and mounted. Vimentin and cytokeratin intensities were assessed using the light microscope with Optilab ${ }^{\circledR}$ camera and were analyzed semiquantitatively.

\section{Results}

\section{Sperm count, motility, and morphology}

The sperm motility of the low-dose group had individual progressive movement, and no changes were observed after the first, second, and third administration of secretome. However, the sperm of the high-dose group had thin waves and rare and slow movements after the second, third, and fourth administration of secretome (Table-2). No abnormal sperm morphology was observed in all the treated groups after the administration. Figure-1 shows the normal sperm morphology of the control, low-dose, and highdose groups 1 week after the first and third administration of secretome.

Table-3 shows that the number of spermatozoa decreased 1 week after the second secretome injection and then increased 1 week after the third secretome injection in the low-dose group. By contrast, the number of spermatozoa gradually increased 1 week after the first administration of secretome until the last secretome injection in the high-dose group. The number of spermatozoa in the high-dose group was higher 
than that in the control group 1 week after the third administration of secretome.

\section{Morphology of the spermatogenic cells in the semi-} niferous tubules

Figure-2 shows the morphology of the normal spermatogenic cells in the seminiferous tubules of the control group. The complete stage of spermatogenic cells and spermatozoa was observed in the lumen of the normal seminiferous tubules. The cisplatin-induced group had damaged seminiferous tubules, as indicated by the incomplete development stage of spermatogenic cells. The loss of spermatogonia and Sertoli cells was observed in the basal membrane of the seminiferous tubules.

One week after the first administration of secretome, the low-dose group had incomplete spermatogenic cells, as indicated by few spermatogonia and spermatozoa in the basal membrane and lumen of the seminiferous tubules, respectively (Figure-3A1). The seminiferous tubules of the high-dose group were still damaged. However, the spermatogenic cells were denser than that of the low-dose group. The number of spermatogenic cells in the first stage of spermatogenesis (primary spermatocytes) was low in the high-dose group. However, the spermatogonia were complete, and several spermatozoa were observed in the lumen of the seminiferous tubules (Figure-3A2).

One week after the second administration of secretome, tissue repair was observed in the low- and high-dose groups, as indicated by the structural improvement in the seminiferous tubules. Spermatogonia were observed in the basal membrane. Furthermore, the presence of primary spermatocytes and Leydig cells was observed in both the groups. However, spermatozoa were denser in the lumen of the seminiferous tubules of the high-dose group than those of the low-dose group (Figure-3B1 and B2). The spermatogenic cells of the low- and high-dose groups completely developed 1 week after the third administration of secretome. However, no spermatozoa were observed in the seminiferous tubules of the low-dose group (Figure-3C1 and C2). 1 week after the fourth secretome injection, the spermatogenic cells and spermatozoa in the lumen of the seminiferous tubules of the high-dose group completely developed (Figure-3D1). Data about the effects of the last injection in the low-dose group were not obtained.

\section{Vimentin and cytokeratin immunolocalization in the seminiferous tubules}

Vimentin immunoreactivity in the normal seminiferous tubules was very strong, particularly in the primary spermatocytes and spermatozoa

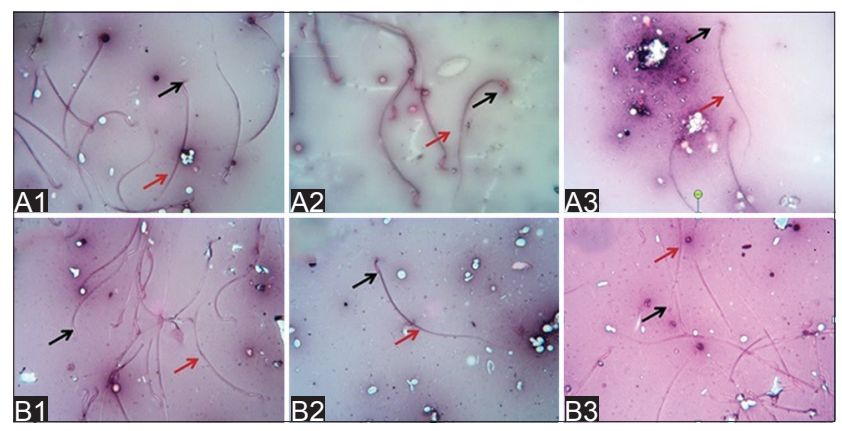

Figure-1: Sperm morphology of the secretome-treated group (eosin and nigrosin stain; 500× magnification). No abnormal sperm morphology was observed in the control group (1), low-dose group (2), and high-dose group (3) 1 week after the first (A) and third (B) secretome injections. The head (black arrow) and tail (red arrow) of the sperm showed the normal morphology.
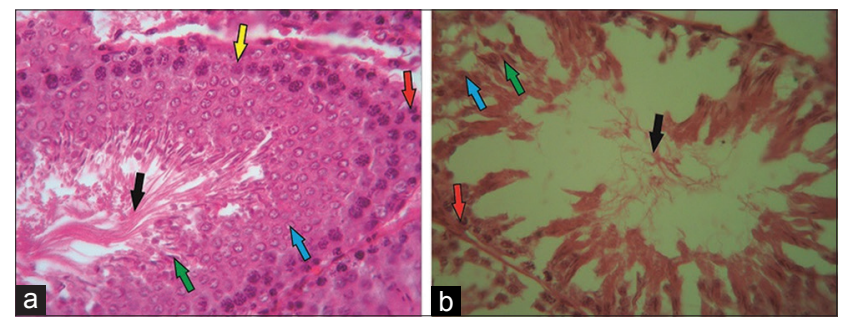

Figure-2: Normal (a) and cisplatin-induced seminiferous tubules (b) ( $H \& E, 500 \times)$. Spermatogonia (red arrow), primary spermatocytes and spermatids (blue and green arrow), spermatozoa (black arrow), and Sertoli cells (yellow arrow) were observed in the normal seminiferous tubules. Conversely, severe damage was observed in the cisplatin-induced seminiferous tubules.

Table-2: Sperm motility grading in the control and secretome-treated groups.

\begin{tabular}{lcccc}
\hline Group & $\begin{array}{c}\mathbf{1} \text { week after the first } \\
\text { treatment }\end{array}$ & $\begin{array}{c}\mathbf{1} \text { week after the second } \\
\text { treatment }\end{array}$ & $\begin{array}{c}\mathbf{1} \text { week after the third } \\
\text { treatment }\end{array}$ & $\begin{array}{c}\mathbf{1} \text { week after the fourth } \\
\text { treatment }\end{array}$ \\
\hline Control & +++ & +++ & + & +++ \\
Low dose & + & ++ & + & +++ \\
High dose & + & ++ & ++ \\
\hline
\end{tabular}

$\mathrm{ND}=$ No data

Table-3: Number of spermatozoa per $\mathrm{ml}$ in the control and secretome-treated groups.

\begin{tabular}{lcccc}
\hline Group & $\begin{array}{c}\mathbf{1} \text { week after the first } \\
\text { treatment }\end{array}$ & $\begin{array}{c}\text { 1 week after the second } \\
\text { treatment }\end{array}$ & $\begin{array}{c}\text { 1 week after the third } \\
\text { treatment }\end{array}$ & $\begin{array}{c}\text { 1 week after the fourth } \\
\text { treatment }\end{array}$ \\
\hline Control & $180 \times 10^{6}$ & $214 \times 10^{6}$ & $181 \times 10^{6}$ & $315 \times 10^{6}$ \\
Low dose & $47 \times 10^{6}$ & $21 \times 10^{6}$ & $34 \times 10^{6}$ & $N D$ \\
High dose & $72 \times 10^{6}$ & $190 \times 10^{6}$ & $260 \times 10^{6}$ & $307 \times 10^{6}$ \\
\hline
\end{tabular}

$\mathrm{ND}=$ No data 
(Figure-4A1). Meanwhile, cytokeratin immunoreactivity was observed in the normal seminiferous tubules. However, localization was observed in

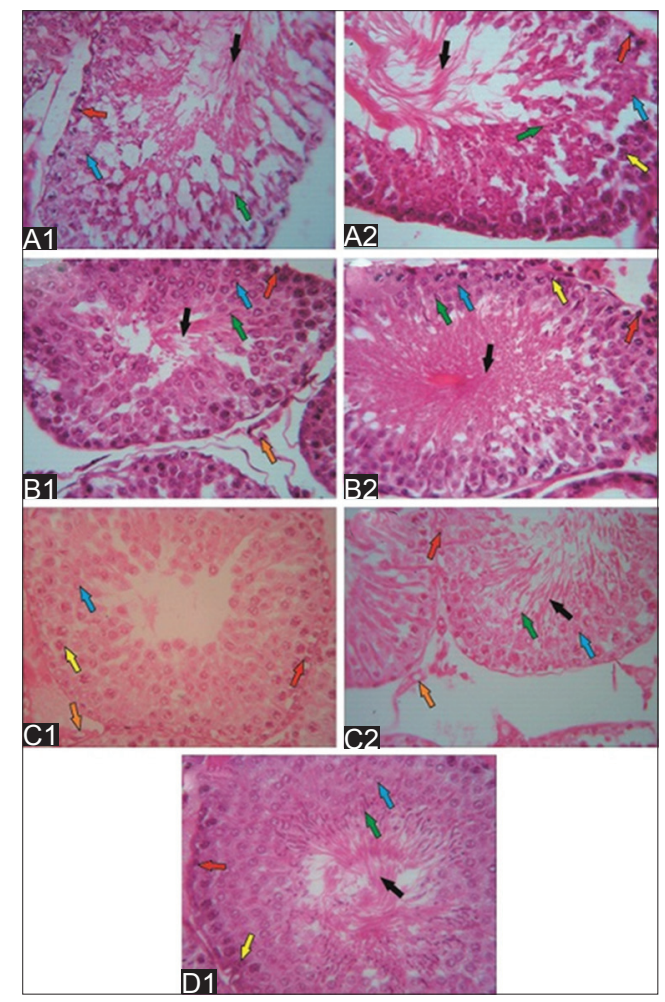

Figure-3: The structure of seminiferous tubules after secretome injection in the low- and high-dose groups (hematoxylin and eosin staining; 500x). 1 week after secretome injection, few spermatogonia (red arrow) and spermatozoa (black arrow) were observed in the lowdose group (A1), and few primary spermatocytes (blue arrow) were observed in the high-dose group (A2). The regenerative effects were observed in both groups 1 week after the second secretome injection. That is, the spermatogenic cells were complete. However, spermatozoa were denser in the seminiferous tubules (B2) of the highdose group than in those of the low-dose group (B1). 1 week after the third secretome injection, low- and highdose group (C1 and $\mathrm{C} 2$ ) showed complete spermatogenic cells. However, no spermatozoa were noted in the low-dose group. 1 week after the fourth secretome injection in the high-dose group (D1), the complete stage of spermatogenic cells and spermatozoa was observed in the lumen of the seminiferous tubules. several spermatogenic cells (Figure-4B1). After the administration of cisplatin, vimentin and cytokeratin immunoreactivities were not observed. In addition, the structures of the seminiferous tubules were damaged (Figure-4A2 and B2).

Based on the semiquantitative analysis, vimentin and cytokeratin intensities in the seminiferous tubules are shown in Table-4. 1 week after the first secretome injection, the vimentin immunoreactivity of the lowdose group was weak in the spermatogonia, moderate in the primary spermatocytes and strong in the spermatozoa and Sertoli cells (Figure-5A1). In the highdose group, vimentin immunoreactivity was weak in the primary spermatocytes and moderate in the spermatid and Sertoli cells (Figure-5A2). Vimentin immunoreactivity was not observed in the Leydig cells of the two groups. 1 week after the second secretome injection in the low-dose group, vimentin immunoreactivity was weak in the spermatogonia, moderate in the primary spermatocytes and strong in the spermatozoa, Sertoli cells, and Leydig cells (Figure-5B1). Meanwhile, in the high-dose group, vimentin immunoreactivity in the spermatogonia and Leydig cells, spermatocytes, and spermatozoa and Sertoli cells was strong, moderate, and extremely strong, respectively (Figure-5B2). 1 week after the third secretome injection in the low-dose group, vimentin immunoreactivity in the primary spermatocytes and Leydig cells and spermatozoa and Sertoli cells were weak and moderate, respectively. However, vimentin immunoreactivity was not observed in the spermatogonia (Figure-5C1). In the high-dose group, vimentin immunoreactivity was weak in the spermatogonia and primary spermatocytes. It was moderate in the Leydig cells and strong in the spermatozoa and Sertoli cells (Figure-5C2). After the last secretome injection, vimentin immunoreactivity in the primary spermatocyte and Leydig cells was weak, and that in the spermatozoa and Sertoli cells was moderate. However, it was not observed in the spermatogonia (Figure-5D1).

1 week after the first secretome injection in the low-dose group, cytokeratin immunoreactivity was weak in the spermatozoa and Sertoli cells

Table-4: Semiquantitative analysis of vimentin and cytokeratin immunoreactivity in the low- and high-dose groups.

\begin{tabular}{|c|c|c|c|c|c|c|c|c|c|}
\hline \multirow[t]{2}{*}{$\begin{array}{l}\text { Spermatogenic } \\
\text { cells }\end{array}$} & \multirow[t]{2}{*}{ Cytoskeleton } & \multicolumn{2}{|c|}{$\begin{array}{l}1 \text { week after the } \\
\text { first secretome } \\
\text { injection }\end{array}$} & \multicolumn{2}{|c|}{$\begin{array}{c}1 \text { week after the } \\
\text { second secretome } \\
\text { injection }\end{array}$} & \multicolumn{2}{|c|}{$\begin{array}{c}1 \text { week after the } \\
\text { third secretome } \\
\text { injection }\end{array}$} & \multicolumn{2}{|c|}{$\begin{array}{c}1 \text { week after the } \\
\text { fourth secretome } \\
\text { injection }\end{array}$} \\
\hline & & Low & High & Low & High & Low & High & Low & High \\
\hline \multirow[t]{2}{*}{ Spermatogonia } & Vimentin & + & + & + & +++ & + & + & ND & - \\
\hline & Cytokeratin & - & - & ++ & + & - & ++ & ND & ++ \\
\hline Primary & Vimentin & ++ & + & ++ & ++ & + & + & ND & + \\
\hline spermatocytes & Cytokeratin & - & + & ++ & + & + & ++ & ND & + \\
\hline \multirow[t]{2}{*}{ Spermatozoa } & Vimentin & +++ & ++ & +++ & ++++ & ++ & +++ & ND & ++ \\
\hline & Cytokeratin & + & + & ++ & ++ & + & ++ & ND & +++ \\
\hline \multirow[t]{2}{*}{ Sertoli cells } & Vimentin & +++ & ++ & +++ & ++++ & ++ & +++ & ND & ++ \\
\hline & Cytokeratin & - & + & ++ & ++ & ++ & +++ & ND & +++ \\
\hline \multirow[t]{2}{*}{ Leydig cells } & Vimentin & - & - & +++ & +++ & + & ++ & ND & + \\
\hline & Cytokeratin & - & + & +++ & ++++ & + & +++ & ND & +++ \\
\hline
\end{tabular}

$-=$ Negative,$+=$ Weak,$++=$ Moderate,$+++=$ Strong, $++++=$ Very strong, $N D=$ No data 


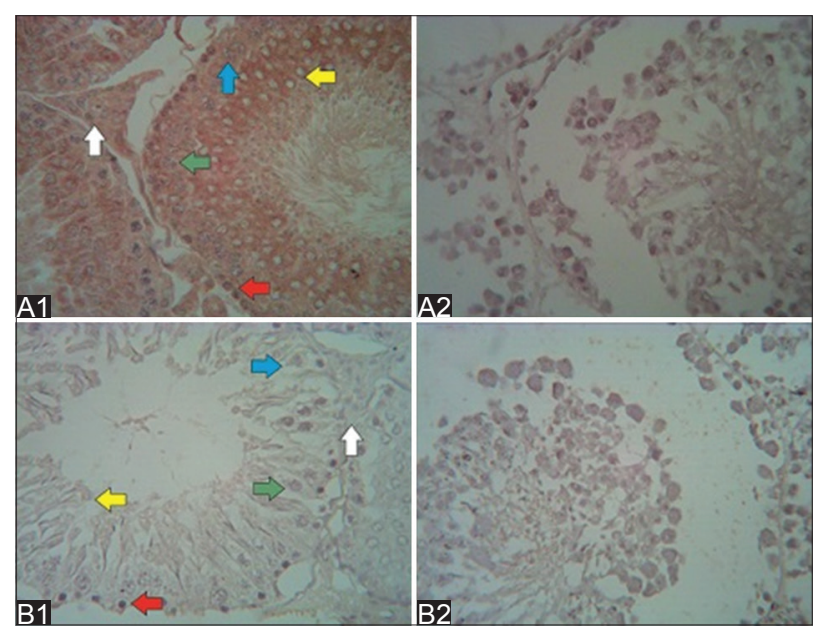

Figure-4: Vimentin and cytokeratin immunoreactivity in the normal and cisplatin-induced seminiferous tubules (immunohistochemistry; 500x). Very strong vimentin immunoreactivity was found in the normal spermatogenic cells (A1), and cytokeratin immunoreactivity was observed in several spermatogenic cells (B1). Moreover, no vimentin immunoreactivity (A2) and cytokeratin immunoreactivity (B2) were observed after cisplatin administration.

(Figure-6A1). Meanwhile, in the high-dose group, cytokeratin immunoreactivity was weak in the spermatozoa, Sertoli cells, and Leydig cells (Figure-6A2). 1 week after the second secretome injection in the lowdose group, cytokeratin immunoreactivity was moderate in the spermatogonia, primary spermatocytes, spermatozoa, and Sertoli cells, and it was strong in the Leydig cells (Figure-6B1). In the high-dose group, cytokeratin immunoreactivity was weak in the spermatogonia and primary spermatocytes. Meanwhile, cytokeratin immunoreactivity was moderate in the spermatozoa and Sertoli cells and very strong in the Leydig cells (Figure-6B2). 1 week after the third secretome injection in the low-dose group, cytokeratin immunoreactivity was weak in the spermatogonia, primary spermatocytes, spermatozoa, and Leydig cells. However, it was moderate in the Sertoli cells (Figure-6C1). In the high-dose group, cytokeratin immunoreactivity was moderate in the spermatogonia and spermatozoa and strong in the Sertoli and Leydig cells (Figure-6C2). 1 week after the last secretome injection in the high-dose group, cytokeratin immunoreactivity was weak in the primary spermatocytes, moderate in the spermatogonia and strong in the spermatozoa, Sertoli cells, and Leydig cells (Figure-6D1).

\section{Discussion}

Testicular toxicity is one of the serious side effects of cisplatin, which is used in chemotherapy [12]. Parenchymal atrophy in the seminiferous tubules had been reported after the administration of cisplatin [13], which causes loss of spermatogonia [14], abnormalities in the Leydig cells [6,15], and suppression of testosterone production $[10,14]$. This condition could progress to testicular dysfunction. In the present study, damage in the testicular structure was observed in rats

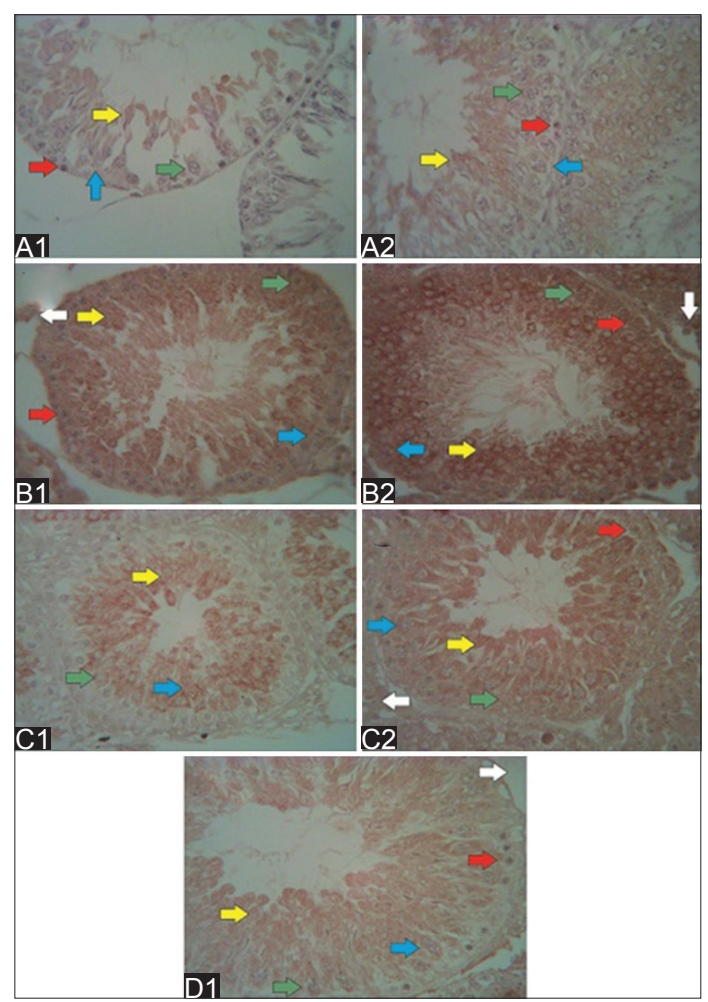

Figure-5: Vimentin immunoreactivity after secretome injection (immunohistochemistry; 500 $\times$ magnification). In the low-dose group (A1), 1 week after the first secretome injection, a strong vimentin immunoreactivity was observed in the spermatozoa (yellow arrow) and Sertoli cells (blue arrow), whereas in the high-dose (A2) group, the immunoreactivity was moderate. In the low-dose group (B1), 1 week after the second secretome injection, a strong vimentin immunoreactivity was still observed in the spermatozoa and Sertoli cells. Meanwhile, in the highdose group (B2), the immunoreactivity was very strong in the same cell. In the low-dose group (C1), 1 week after the third secretome injection, moderate vimentin immunoreactivity was observed in the spermatozoa and Sertoli cells, whereas in the high-dose group (C2), the immunoreactivity was strong in the same cells. Then, 1 week after the last injection in the high-dose group (D1), the vimentin immunoreactivity was moderate in the spermatozoa and Sertoli cells. Spermatogonia (red arrow), primary spermatocytes (green arrow), and Leydig cells (white arrow).

after the administration of $3 \mathrm{mg} / \mathrm{kg}$ BW cisplatin intraperitoneally 3 times with 3 days' interval. Cisplatininduced testicular damage was characterized by cell apoptosis, Leydig cell dysfunction, and infertility [16]. This condition caused the inhibition of testosterone production and spermatogenesis. Cisplatin-induced testicular cell damage is caused by oxidative stress [6], which induces cellular damage by the generation of reactive oxygen species [10]. Oxidative stress could progressively damage the DNA and interfere with cell replication and transcription. Cisplatin also suppresses antioxidant enzyme activity and increases hydrogen peroxide and lipid peroxide levels in the testes and epididymis $[14,17]$. Severe testicular toxicity induced by cisplatin was infaust diagnosed [16]. This pathogenesis could explain the process of cell damage induced by cisplatin. 


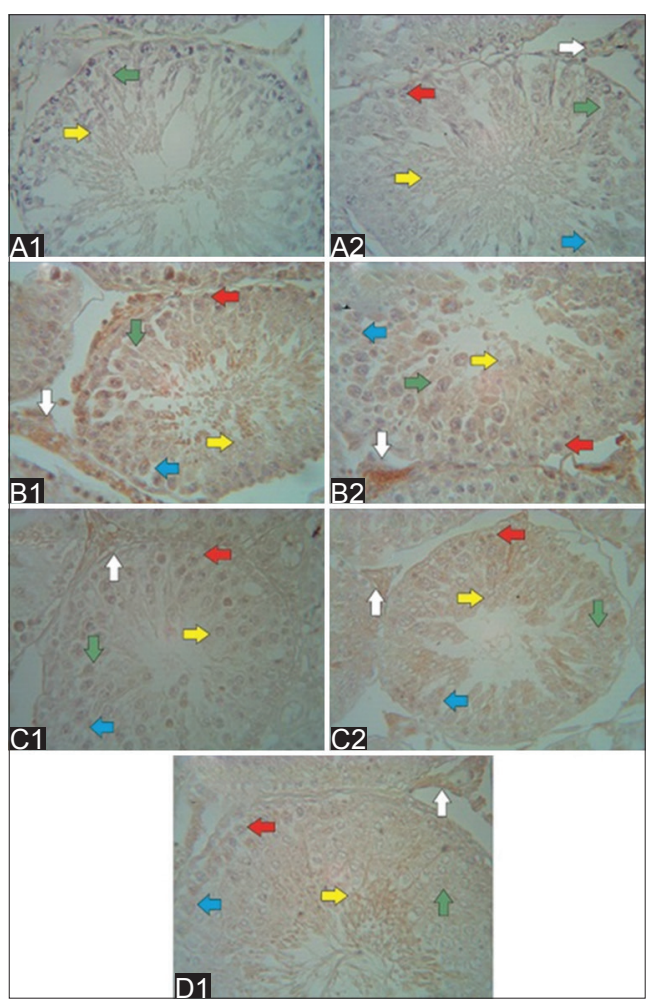

Figure-6: Cytokeratin immunoreactivity after secretome injection (immunohistochemistry; 500x magnification). In the low-dose group (A1), 1 week after the first secretome injection, a weak cytokeratin immunoreactivity was observed in the spermatozoa (yellow arrow), whereas in the high-dose group (A2), the immunoreactivity was weak in all spermatogenic cells, Sertoli cells (blue arrow), and Leydig cells (white arrow). In the low-dose group (B1), 1 week after the second secretome injection, a strong cytokeratin immunoreactivity was observed in the Leydig cells, whereas in the high-dose group (B2), very strong immunoreactivity was noted in the Leydig cells. In the low-dose group (C1), 1 week after the third secretome injection, moderate cytokeratin immunoreactivity was observed in the spermatozoa and Sertoli cells, whereas in the high-dose group (C2), a strong immunoreactivity was found in the Sertoli and Leydig cells. Then, 1 week after the last injection, the high-dose group (D1) showed a strong cytokeratin immunoreactivity in the spermatozoa and Sertoli and Leydig cells.

The decrease in sperm motility and number was observed in rats with testicular dysfunction induced by cisplatin. This finding showed that cisplatin deteriorated sperm quality and spermatogenesis $[7,18]$. However, in the present study, no abnormal sperm morphology was observed. On the contrary, the administration of cisplatin 15 times could cause various abnormalities in the head and tail of sperms [14]. The administration of cisplatin for 3 times did not cause sperm abnormalities. High-dose secretome might promote the regeneration of spermatogenic and Leydig cells. 1 week after the first, second, third, and fourth secretome injections, the number and motility of the sperms gradually increased in the high-dose group.

In the present study, the regenerative effect of secretome is characterized by the presence of spermatogenesis. Histologically, complete spermatogenic cells in the seminiferous tubules were gradually observed in the low-dose group after the $3^{\text {rd }}$ secretome injection and in the high-dose group after the fourth secretome injection. Spermatogenic cells could be observed and distinguished, and spermatogonia in the basal membrane would involve the primary spermatocytes in the mitotic stage. In both the groups, secondary spermatocytes were not observed due to the rapid meiotic stage of the spermatozoa in the seminiferous tubules [19]. In addition, the regeneration of Sertoli and Leydig cells was also observed. Sertoli cells play a primary role in spermatogenesis and testosterone production [20]. Spermatogenic, Sertoli, and Leydig cells were correlated to each other in terms of spermatogenesis and testosterone synthesis. Testicular dysfunction might interfere with spermatogenesis and testosterone synthesis due to cell damage. Secretome derived from the HUC-MSC can migrate, proliferate, and differentiate in the tissues or cells for regenerative process $[21,22]$. The regeneration of spermatogenic, Sertoli, and Leydig cells in the seminiferous tubules can be caused by growth factors and cytokines contained in the secretome.

The effects of secretome also supported the presence of cytoskeletal proteins in the spermatogenic cells after secretome injection. The following are the three major cytoskeletal proteins: Microfilament, intermediate filament, and microtubules. Vimentin and cytokeratin, which are intermediate filaments, were observed in this present study. In normal conditions, during the developmental stage, vimentin was detected in the Sertoli cells of both fetuses and adults [23-26]. The maturation of Sertoli cells was supported by the presence of vimentin in the cells. Membrane formation, which is known as the desmosome-like junction formed by vimentin, would connect the Sertoli cells with the adjacent germinal cells in the seminiferous tubules. Vimentin distribution depends on the spermatogenesis cycle, and they would be distributed along with the head of the spermatozoa. Vimentin would maintain the integrity of the spermatogenic cells and their connection [27]. Another study has reported that vimentin was also found in the Leydig cells of mature or immature testes [28]. In this present study, 1 week after the second secretome injection, vimentin immunoreactivity was strong in the spermatogonia. Vimentin immunoreactivity in primary spermatocytes, spermatozoa, Sertoli cells, and Leydig cells increased and then decreased dynamically in both the groups every 1 week after the injection. However, an extremely strong vimentin immunoreactivity was observed in the spermatozoa, Sertoli cells, and Leydig cells 1 week after the second secretome injection at high dose. Vimentin was observed in the spermatogenic, Sertoli, and Leydig cells because vimentin supported and controlled the cell structure and function of fetuses or adults [26]. Very strong vimentin immunoreactivity indicated a regenerative process. 
Cytokeratin in rats was observed in the spermatogenic, Sertoli, and Leydig cells [23-26]. Cytokeratin was found in the Sertoli cells during the development stage only. However, sometimes, it was observed before the last spermatogenesis stages. Another study has reported that cytokeratin had not been observed in spermatogenic cells. However, it was noted during the pre-meiotic, meiotic, and post-meiotic stages [29]. This result was contrary to that in this study. Cytokeratin immunoreactivity in the Sertoli cells was moderate in the low-dose group 1 week after the second secretome injection. Meanwhile, it increased gradually and was strong in the high-dose group 1 week after the third secretome injection. Then, it decreased after the last injection. The dynamic increase and decrease in cytokeratin immunoreactivity were observed in the spermatogonia, primary spermatocytes, spermatozoa, and Leydig cells every 1 week after injection. However, in the Leydig cells, very strong immunoreactivity was detected in the high-dose group 1 week after the second secretome injection. Secretome that contains growth factors and cytokines, which are regenerative agents, might play a role in the formation of cytokeratin in adult rats with cisplatin-induced testicular dysfunction. The dynamic increase and decrease in the immunoreactivity of vimentin and cytokeratin might be caused by high inflammation reaction by endogenous cytokines. The use of secretome in diabetic rat could repair $\beta$-cells of the treatment which is provided earlier. However, it could not maintain the $\beta$-cells if the treatment is provided later. It was suggested that exogenous tumor necrosis factor- $\alpha$ and interleukin (IL) in secretome would stimulate severe inflammation reaction [30]. Severe inflammation might inhibit vimentin and cytokeratin formation. In normal conditions, Leydig cells might secrete cytokines, such as IL-1 and IL-6. Macrophages were present in the testicular interstitium, and they may stimulate Leydig cells to produce cytokines [31,32]. An in vitro study has reported that IL-1 and IL-6 also influenced the Sertoli cells [33]. However, the structures of the seminiferous tubules and cell morphology were normal.

Secretome derived from the MSC culture medium contains growth factors and cytokines [21,22]. The various growth factors and cytokines which were secreted by various stem cells in the conditioned medium [34] might play a role in cell regeneration [1]. In this study, growth factors and cytokines in secretomes derived from HUC-MSC play a role in cell regeneration through a paracrine mechanism.

\section{Conclusion}

High-dose secretomes derived from the human fetal umbilical cord could help to increase the number and motility of sperms in rats with cisplatin-induced testicular dysfunction. Secretome injections were effective 1 week after the second secretome injection that was administered at the high dose. That is, the immunoreactivity of vimentin and cytokeratin was very strong. However, secretome could promote the regeneration of seminiferous tubules in both the groups.

\section{Authors' Contributions}

SAP developed the concepts and designed the experiments, evaluated the spermatozoa, and wrote the manuscript. IP processed testicle tissues for a paraffin-embedded method and visualized vimentin and cytokeratin using immunohistochemical method. ADL created testicular dysfunction in rat with cisplatin-treated rats with secretome. BS performed euthanization of rats, collected testes, fixed sample in Bouin, and evaluated the spermatozoa. AH stained the tissues structures using $\mathrm{H} \& \mathrm{E}$ method. YHF produced the secretome. TB developed the concepts and designed the experiments and analyzed and interpreted the data. All authors read and approved the final manuscript.

\section{Acknowledgments}

Authors would like to thank the Directorate General of Higher Education, Ministry of Research, Technology and Higher Education for fully funding this study (Grant number: 160/UN1/DITLIT/ DIT-LIT/LT/2017). Authors would also like to thank the Department of Anatomy and Laboratory of Microanatomy that supported and facilitated this study.

\section{Competing Interests}

The authors declare that they have no competing interests.

\section{References}

1. Pawitan, J.A. (2014) Prospect of stem cell conditioned medium in regenerative medicine. Biomed. Res. Int., 2014: 1-14.

2. Nugroho W.S., Kusindarta, D.L., Susetya, H., Fitriana, I., Mulyani, G.T., Fibrianto, Y.H., Haryanto, A. and Budipitojo, T. (2016) The structural and functional recovery of pancreatic B-cells In Type 1 diabetes mellitus induced mesenchymal stem cell-conditioned medium. Vet. World, 9(5): 535-539.

3. Kusindarta, D.L., Wihadmadyatami, H., Fibrianto, Y.H., Nugroho, W.S., Susetya, H., Musana, D.K., Wijayanto, H., Prihatna, S.A. and Wahyuni, A.E.T.H. (2016) Human umbilical mesenchymal stem cells conditioned medium promote primary wound healing regeneration. Vet. World, 9(6): 605-610.

4. Padeta, I., Nugroho, W.S., Kusindarta, D.L., Fibrianto, Y.H. and Budipitojo, T. (2017) Mesenchymal stem cell-conditioned medium promote the recovery of skin burn wound. Asian J. Anim. Vet. Adv., 12(3): 132-141.

5. Koster, R., Van Vugt, M.A.T.M., Timmer-Bosscha, H., Gietema, J.A. and de Jong, S. (2013) Unravelling mechanisms of cisplatin sensitivity and resistance in testicular cancer. Expert. Rev. Mol. Med., 15: e12.

6. Amin, A., Abraham, C., Hamza, A.A., Abdalla, Z.A., Al-Shamsi, S.B. and Harethi, S.S. (2012) A standardized extract of Ginkgo biloba neutralizes cisplatin-mediated reproductive toxicity in rats. Biomed. Res. Int., 2012: 1-11.

7. Beytur, A., Ciftci, O., Oguz, F., Oguzturk, H. and Yilmaz, F. (2012) Montelukast attenuates side effects of cisplatin including testicular, spermatological, and hormonal damage in male rats. Cancer Chemoth. Pharm., 69: 207-213. 
8. Jahnukainen, K., Ehmcke, J., Hou, M. and Schlatt, S. (2011) Testicular function and fertility preservation in male cancer patients. Best. Pract. Res. Clin. Endocrinol. Metab., 25: 287-302

9. Rives, N., Perdrix, A., Hennebicq, S., Saias-Magnan, J., Melin, M.C. and Berthaut, I. (2012) The semen quality of 1158 men with testicular cancer at the time of cryopreservation: Results of the French national CECOS network. J. Androl., 33: 1394-1401.

10. Ahmed, E.A., Omar, H.M., Ragb, S.M. and Nasser, A.Y. (2011) The antioxidant activity of vitamin C, DPPD and L-cysteine against cisplatin-induced testicular oxidative damage in rats. Food Chem. Toxicol., 49: 1115-1121.

11. Reddy, Y.V.K., Reddy, P.S. and Shivalingam, M.R. (2010) Cisplatin or carboplatin caused suppression in antioxidant enzyme defense system in liver, kidney and testis of male albino rats. J. Biomed. Sci. Res., 2(1): 23-28.

12. Madhu, P., Reddy, K.P. and Reddy, P.S. (2016) Role of melatonin in mitigating chemotherapy-induced testicular dysfunction in wistar rats. Drug Chem. Toxicol., 39(2): 137-146.

13. Atessahin, A., Sahna, E. and Turk, G. (2006) Chemoprotective effect of melatonin against cisplatin-induced testicular toxicity in rats. J. Pineal Res., 41: 21-27.

14. Reddy, K.P., Madhu, P. and Reddy, P.S. (2016) Protective effects of resveratrol against cisplatin-induced testicular and epididymal toxicity in rats. Food Chem. Toxicol., 91: 65-72.

15. Boekelheide, K. (2005) Mechanisms of toxic damage to spermatogenesis. J. Natl. Canc. Inst. Monogr., 34: 6-8.

16. Soni, K.K., Zhang, L.T., You, J.H., Lee, S.W., Kim, C.Y., Cui, W.S., Chae, H.J., Kim, H.K. and Park, J.K. (2015) The effects of motiliperm on cisplatin-induced testicular toxicity in Sprague-Dawley rats. Cancer Cell Int., 15: 121.

17. Al-Bader, M. and Kilarkaje, N. (2015) Effects of bleomycin, etoposide and cisplatin treatment on Leydig cell structure and transcription of steroidogenic enzymes in rat testis. Eur. J. Pharmacol., 747: 150-159.

18. Ciftci, O., Beytur, A., Cakir, O., Gurbuz, N. and Vardi, N. (2011) Comparison of reproductive toxicity caused by cisplatin and novel platinum-N-heterocyclic carbene complex in male rats. Basic Clin. Pharmacol. Toxicol., 109: 328-333.

19. Eroschenko, V.P. (2010) Atlas Histologi Difiore Dengan Korelasi Fungsional. Penerbit Buku Kedokteran EGC, Jakarta. p423-439.

20. Kianifard, D., Sadrkhanlou, R.A. and Hasanzadeh, S. (2011) The ultrastructural changes of the Sertoli and Leydig cells following streptozotocin induced diabetes. Iran J. Basic Med. Sci., 15(1): 623-635.

21. Maxson, S., Lopez, E.A., Yoo, D. and Miagkova, A.D. (2012) Concise review: Role of mesenchymal stem cells in wound repair. Stem. Cells Transl. Med., 1(2): 142-149.

22. Han, Y., Chai, J., Sun, T., Li, D. and Dongjie, T.R. (2011) Differentiation of human umbilical cord mesenchymal stem cells into dermal fibroblast in vitro. Biochem. Biophys. Res. Comm., 413: 661-565.

23. Paranko, J., Kallajoki, M., Pelliniemi, L.J., Lehto, V.P. and Virtanen, I. (1986) Transient coexpression of cytokeratin and vimentin in differentiating rat Sertoli cells. Dev. Biol., 117: $35-44$

24. Frojdman, K., Paranko, J., Virtanen, I. and Pelliniemi, L.J. (1992) Intermediate filaments and epithelial differentiation of male rat embryonic gonad. Differentiation, 50: 113-123.

25. Rogatsch, H., Jezek, D., Hittmair, A., Mikuz, G. and Feichtinger, H. (1996) Expression of vimentin, cytokeratin, and desmin in Sertoli cells of human fetal, cryptorchid, and tumor-adjacent testicular tissue. Virchows Arch., 427: 497-502.

26. Sasaki, M., Yamamoto, M., Arishima, K. and Eguchi, Y. (1998) Effects of follicle-stimulating hormone on intermediate filaments and cell division of Sertoli cells of fetal rat testis in culture. J. Vet. Med. Sci., 60: 35-39.

27. Kume, E., Yuya, O., Mituru, S., Hiroyuki, T., Tomoko, M., Michael, F.W., Hiroshi, I. and Shin, W. (2017) Quantitative morphometric analysis of vimentin filament in Sertoli cell of rats after in utero dbp exposure. Fundam. Toxicol. Sci. 4(2): 85-93.

28. Gerber, J. (2015) Investigation of The Junctional Complex at the Blood-Testis Barrier in Sccx43ko Mice and Establishment and Functional Characterization of a Murine Sertoli Cell Line Deficient of Connexin43. InauguralDissertation Zur Erlangung Des Grades Eines Doktors Der Naturwissenschaften, Hannover.

29. Kierszenbaum, A.L., Rivkin, E., Fefer-Sadler, S., Mertz, J.R. and Tres, L.L. (1996) Purification, partial characterization, and localization of Sak57 and acidic intermediate filament keratin present in rat spermatocytes, spermatids and sperm. Mol. Reprod. Dev., 44(3): 392-394.

30. Budipitojo, T., Padeta, I., Nugroho, W.S. and Fitriana, I. (2018) Temporal recovery of pancreatic $\beta$-cells in Type 2 diabetes mellitus induced by mesenchymal stem cell-conditioned medium. Adv. Life Sci. Tech., 62: 14-19.

31. Lin, T., Wang, D. and Nagpal, M.L. (1993) Human chorionic gonadotropin induces interleukin-1 gene expression in rat Leydig cells in vivo. Mol. Cell. Endocrinol., 95: 139-145.

32. Okuda, Y., Sun, X.R. and Morris, P.L. (1994) Interleukin-6 (IL-6) mRNAs expressed in Leydig and Sertoli cells are regulated by cytokines, gonadotropins and neuropeptides. Endocr. J., 2: 617-624.

33. Cudicini, C., Lejeune, H., Gomez, E., Bosmans, E., Ballet, F., Saez, J. and Jegou, B. (1997) Human Leydig cells and Sertoli cells are producers interleukins-1 and-6. J. Clin. Endocrinol. Metabol., 82(5): 1426-1433.

34. Bhang, S.H., Lee, S., Shin, J.Y., Lee, T.J., Jang, H.K. and Kim, B.S. (2014) Efficacious and clinically relevant conditioned medium of human adipose-derived stem cells for therapeutic angiogenesis. Mol. Ther., 22(4): 862. 